Original Research

\title{
A Genome-Wide Association Analysis in Noriker Horses Identifies a SNP Associated With Roan Coat Color
}

\author{
Gertrud Grilz-Seger ${ }^{\text {a, }}{ }^{\text {, * }}$, Simone Reiter ${ }^{\text {a, }}{ }^{\text {, Markus Neuditschko }}{ }^{\mathrm{b}}$, Barbara Wallner ${ }^{\mathrm{a}}$, \\ Stefan Rieder ${ }^{c}$, Tosso Leeb ${ }^{\mathrm{d}}$, Vidhya Jagannathan ${ }^{\mathrm{d}}$, Matjaz Mesarič ${ }^{\mathrm{e}}$, Markus Cotman ${ }^{\mathrm{f}}$, \\ Hubert Pausch ${ }^{\mathrm{g}}$, Gabriella Lindgren ${ }^{\mathrm{h}, \mathrm{i}}$, Brandon Velie ${ }^{\mathrm{j}}$, Michaela Horna ${ }^{\mathrm{k}}$, \\ Gottfried Brem ${ }^{\text {, }}$, Thomas Druml ${ }^{1}$
}

\footnotetext{
${ }^{a}$ Department of Animal Breeding and Genetics, University of Veterinary Sciences Vienna, Vienna, Austria

b Agroscope, Avenches, Switzerland

${ }^{\mathrm{c}}$ Identitas AG, Bern, Switzerland

d Department of Genetics, Vetsuisse Faculty, University of Bern, Bern, Switzerland

e Clinic for Reproduction and Large Animals, University of Ljubljana, Veterinary Faculty, Ljubljana, Slovenia

${ }^{\mathrm{f}}$ Department for Preclinical Sciences, University of Ljubljana, Veterinary Faculty, Ljubljana, Slovenia

g Animal Genomics, ETH Zürich, Lindau, Switzerland

${ }^{\mathrm{h}}$ Department of Animal Breeding \& Genetics, Swedish University of Agricultural Sciences, Uppsala, Sweden

${ }^{\mathrm{i}}$ Livestock Genetics, Department of Biosystems, KU Leuven, Leuven, Belgium

j School of Life and Environmental Sciences, University of Sydney, Sydney, New South Wales, Australia

${ }^{\mathrm{k}}$ Department of Animal Husbandry, Slovak University of Agriculture in Nitra, Nitra, Slovakia

${ }^{1}$ Lipizzan stud farm of Piber, Köflach, Austria
}

\section{A R T I C L E I N F O}

\section{Article history:}

Received 21 December 2019

Received in revised form

28 January 2020

Accepted 28 January 2020

Available online 5 February 2020

\section{Keywords:}

Roan

Horse

Coat color

KIT

GWAS

Genetic marker

\begin{abstract}
A B S T R A C T
The roan coat color in horses is characterized by dispersed white hair and dark points. This phenotype segregates in a broad range of horse breeds, while the underlying genetic background is still unknown. Previous studies mapped the roan locus to the KIT gene on equine chromosome 3 (ECA3). However, this association could not be validated across different horse breeds. Performing a genome-wide association analysis (GWAS) in Noriker horses, we identified a single nucleotide polymorphism (SNP) (ECA3:g.79,543.439 A > G) in the intron 17 of the KIT gene. The $G$-allele of the top associated SNP was present in other roan horses, namely Quarter Horse, Murgese, Slovenian, and Belgian draught horse, while it was absent in a panel of 15 breeds, including 657 non-roan horses. In further 379 gray Lipizzan horses, eight animals exhibited a heterozygous genotype $(A / G)$. Comparative whole-genome sequence analysis of the KIT region revealed two deletions in the downstream region (ECA3:79,533,217_79,533,224delTCGTCTTC; ECA3:79,533,282_79,533,285delTTCT) and a 3 bp deletion combined with 17 bp insertion in intron 20 of KIT (ECA3:79,588,128_79,588,130delinsTTATCTCTATAGTAGTT). Within the Noriker sample, these loci were in complete linkage disequilibrium (LD) with the identified top SNP. Based upon pedigree information and historical records, we were able to trace back the genetic origin of roan coat color to a baroque gene pool. Furthermore, our data suggest allelic heterogeneity and the existence of additional roan alleles in ponies and breeds related to the English
\end{abstract}

\begin{abstract}
Author's contribution: Grilz-Seger, Gertrud: conceptualization, writing - original draft, project administration; Reiter Simone: comparative sequence analysis, genotyping, fine-scale mapping; Neuditschko, Markus: formal analysis, visualization; Wallner, Barbara: comparative sequence analysis, fine-scale mapping; Leeb, Tosso: sequencing NO180, Jagannathan, Vidhya.: sequencing NO180, Mesaric, Matjaz: sampling, Cotman, Marko: sampling, DNA extraction; Pausch, Hubert: formal analysis, Lindgren, Gabriella: providing SNP data; Velie, Brandon: providing SNP data; Brem, Gottfried: funding acquisition; Druml, Thomas: formal analysis, Visualization, pedigree analysis, funding acquisition; all authors: reading, commenting and reviewing of the final manuscript draft.

Animal welfare/ethical statement: This study was discussed and approved by the institutional ethics and animal welfare committee in accordance with GSP guidelines and national legislation in protocols by the institutional Commission for Ethics
\end{abstract}

and Animal Welfare, University of Veterinary Medicine, Vienna (ETK-194/12/2019, ETK-06/05/2015) and by the Ethics Committee for Animal Experiments in Uppsala, Sweden (Number: C 121/14). Hair samples for Slovenian Coldblooded Horse, Bosnian Mountain Horse, Posavina, Quarter Horse were collected in the context of routine procedures during the studbook registration of horses by the Institute for Breeding and Health Care of Horses of the Veterinary Faculty, Ljubljana.

Conflict of interest statement: None of the authors has conflicts of interest.

* Corresponding author at: Gertrud Grilz-Seger, Institute of Animal Breeding and Genetics, Department for Biomedical Sciences; University of Veterinary Medicine Vienna, Veterinärplatz 1, A-1210 Vienna, Austria.

E-mail address: gertrud.grilz@vetmeduni.ac.at (G. Grilz-Seger).

1 These two authors equally contributed to this work. 
Thoroughbred. In order to study the roan phenotype segregating in those breeds, further association and verification studies are required.

() 2020 Elsevier Inc. All rights reserved.

\section{Introduction}

The knowledge of coat color genetics in horses rapidly progressed within the last decades. One milestone was the detection of a single missense variant in the equine melanocortin-1-receptor gene $(M C 1 R)$, causative for chestnut coat color by Marklund et al. [1]. With the identification of an 11-bp deletion in exon 2 of the agouti-signaling-protein (ASIP) gene associated with black coat color by Rieder et al. [2], the basic colors of horses could be described on a molecular level. Our knowledge regarding diluted colors was deepened by a series of publications by Mariat et al. (cream, SLC45A2/MATP) [3], Imsland et al. (dun, TBX3) [4], Cook et al. (champagne, SLC36A1) [5], and Brunberg et al. (silver, PMEL) [6]. In 2008 Pielberg et al. [7] successfully identified the causative variant for gray coat color, whereas for the high phenotypic variability of leopard spotting $(L P)$ patterns up to date two genetic factors were identified: the causative variant for $L P$ [8] and the modifier pattern1 (PATN1) [9]. The increasing scientific interest in the white patterns in horses started with the assignment of the Overo spotting pattern to ENDRB [10]. In on-going research, the KIT gene encoding the KIT proto-oncogene, receptor tyrosine kinase, was found to harbor numerous genetic variants, which are responsible for a wide range of white coat color patterns. To date, the patterns Sabino1 [11], Tobiano [12], Dominant White (up to 28 different alleles within KIT) were described by [13-23]. Splashed
White patterns were found to be caused by variants in MITF or PAX3 [17,24].

The causative genetic background for roan coat color, which segregates in a wide range of horse breeds, is still unknown. Marklund et al. [25] proposed KIT as a candidate gene for roan coat color and identified an association between several KIT variants and the roan coat color in Belgian draught horses. The proposed variants could not be verified in other horse breeds (Welsh, Shetland, and Gotland Pony), exhibiting a roan phenotype, which led the authors to conclude that the genetic background of roan coat color may be heterogeneous across breeds. Furthermore, Marklund et al. [25] confirmed the dominant mode of inheritance of the roan allele $R n$ and claimed the lethality of homozygous roan horses, which was already proposed by Hinz and VanVleck [26]. The hypothesis of the lethality in homozygous roan horses currently has been disputed by Sponenberg and Bellone [27], who postulate the existence of homozygous roan horses.

Performing a genome-wide association analysis (GWAS) in Noriker horses, we identified an SNP (AX-103594067, ECA3:g.79,543,439A > G) in intron 17 of the KIT gene with the GAllele associated with roan coat color [28]. Pedigree analysis and offspring ratios supported the homozygous state of $G / G$ roan Noriker horses. Based on these results, a homozygous $G / G$ roan Noriker stallion was identified as a reference animal for further wholegenome sequence analysis [29]. The aim of this study was to

Table 1

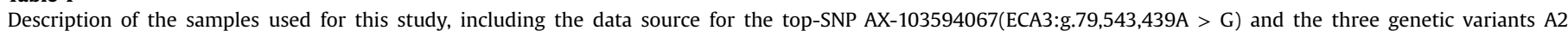
(3:79533214), A3 (3:79533281), B1 (3:79588127-29).

\begin{tabular}{|c|c|c|c|c|}
\hline Non-roan horses & coat color & $\mathrm{N}$ & data source top-SNP & data source genetic variants \\
\hline Akhal Teke & non-roan & 36 & SNP chip & \\
\hline Appaloosa & non-roan & 2 & & genotyping all 4 variants \\
\hline Belgian draught horse & roan & 1 & & genotyping all 4 variants \\
\hline Bosnian Mountain Horse & non-roan & 23 & SNP chip & \\
\hline Exmoor Pony & non-roan & 256 & SNP chip & \\
\hline Franches Montagnes & non-roan & 80 & SNP chip & \\
\hline German Sport horse & non-roan & 1 & & genotyping all 4 variants \\
\hline German Sport horse & roan & 3 & & genotyping all 4 variants \\
\hline Gidran & non-roan & 20 & SNP chip & \\
\hline Lipizzan black/bay & non-roan & 10 & SNP chip & \\
\hline Lipizzan, gray* & non-roan & 379 & SNP chip & \\
\hline Murgese & non-roan & 2 & & genotyping all 4 variants \\
\hline Murgese & roan & 2 & & genotyping all 4 variants \\
\hline Noriker & non-roan & 31 & & genotyping all 4 variants \\
\hline Noriker & non-roan & 7 & SNP chip & genotyping all 4 variants \\
\hline Noriker & non-roan & 119 & SNP chip & \\
\hline Noriker & roan & 26 & & genotyping all 4 variants \\
\hline Noriker & roan & 11 & genotyping top-SNP & \\
\hline Noriker & roan & 14 & SNP chip & \\
\hline Posavina & non-roan & 28 & SNP chip & \\
\hline Quarter Horse & non-roan & 3 & & genotyping all 4 variants \\
\hline Quarter Horse & non-roan & 2 & & genotyping all 4 variants \\
\hline Quarter Horse & roan & 5 & & genotyping all 4 variants \\
\hline Quarter Horse & roan & 2 & SNP chip & genotyping all 4 variants \\
\hline Shagya Arabian & non-roan & 33 & SNP chip & \\
\hline Shetland Pony & non-roan & 2 & & genotyping all 4 variants \\
\hline Shetland Pony & roan & 1 & & genotyping all 4 variants \\
\hline Shetland Pony & roan & 2 & SNP chip & genotyping all 4 variants \\
\hline Slovenian draught horse & roan & 3 & SNP chip & genotyping all 4 variants \\
\hline Trakehner & roan & 1 & & genotyping all 4 variants \\
\hline Trotter & non-roan & 1 & & genotyping all 4 variants \\
\hline All & & 1106 & & \\
\hline
\end{tabular}



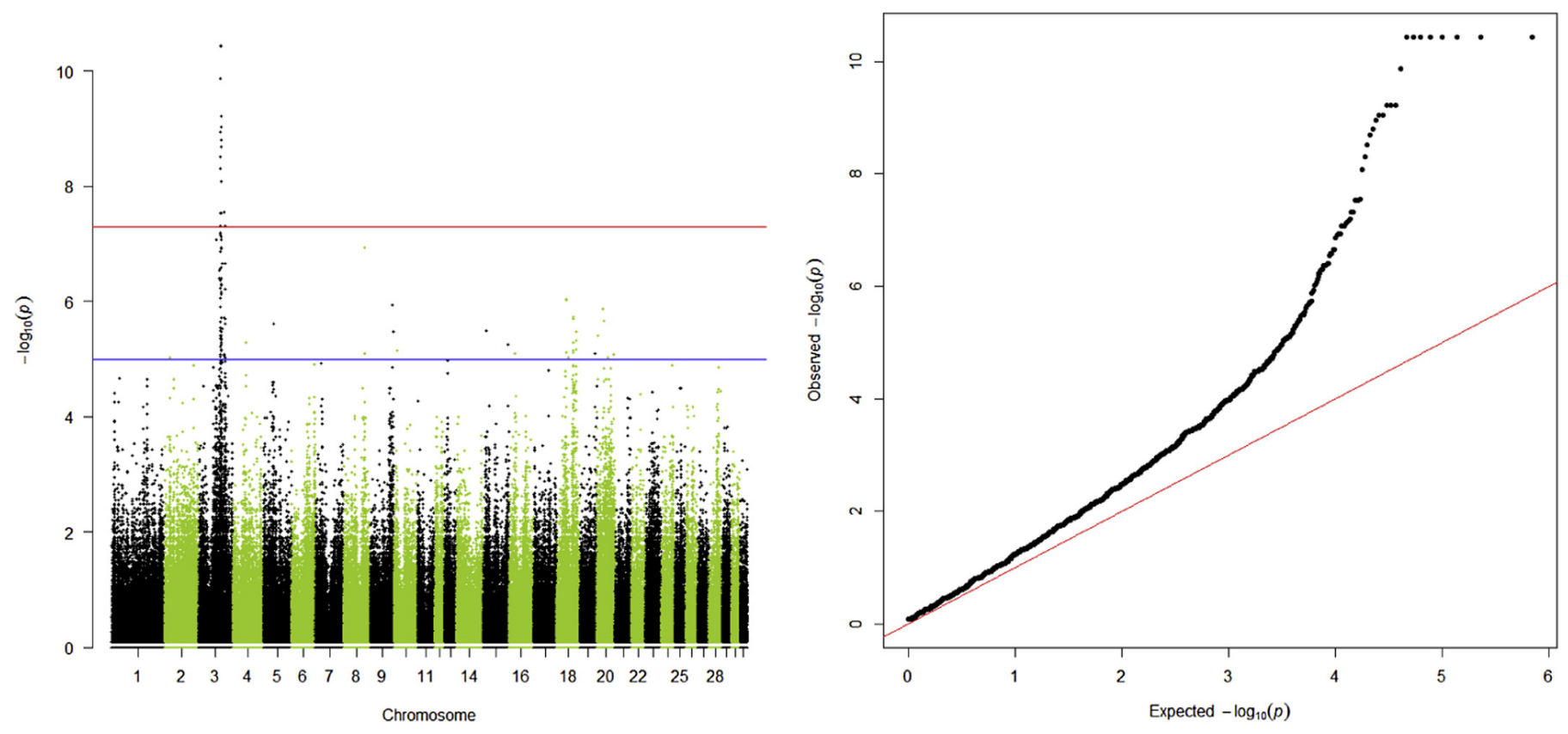

Fig. 1. Manhattan plot and Quantile-Quantile plot for the GWAS of roan versus black Noriker horses.

Table 2

Genotypes for the top-SNP AX-103594067(ECA3:g.79,543,439A > G) for 1035 nonroan/71 roan horses, derived from 670k SNP data and genotyping with KASP technology.

\begin{tabular}{|c|c|c|c|c|}
\hline Non-roan horses & $\mathrm{N}$ & $\begin{array}{l}\text { Genotype } \\
A / A\end{array}$ & $\begin{array}{l}\text { Genotype } \\
A / G\end{array}$ & $\begin{array}{l}\text { Genotype } \\
G / G\end{array}$ \\
\hline Appaloosa & 2 & 2 & 0 & 0 \\
\hline Akhal Teke & 36 & 36 & 0 & 0 \\
\hline Shagya Arabian & 33 & 33 & 0 & 0 \\
\hline Franches Montagnes & 80 & 80 & 0 & 0 \\
\hline $\begin{array}{l}\text { Bosnian Mountain } \\
\text { Horse }\end{array}$ & 23 & 23 & 0 & 0 \\
\hline Posavina & 28 & 28 & 0 & 0 \\
\hline Gidran & 20 & 20 & 0 & 0 \\
\hline Lipizzan black/bay & 10 & 10 & 0 & 0 \\
\hline Lipizzan, gray $^{\mathrm{a}}$ & 379 & 371 & 8 & 0 \\
\hline Quarter Horse & 3 & 3 & 0 & 0 \\
\hline Quarter Horse & 2 & 2 & 0 & 0 \\
\hline Noriker & 31 & 31 & 0 & 0 \\
\hline Noriker & 7 & 7 & 0 & 0 \\
\hline Noriker & 119 & 119 & 0 & 0 \\
\hline Exmoor Pony & 256 & 256 & 0 & 0 \\
\hline Shetland Pony & 2 & 2 & 0 & 0 \\
\hline German Sport horse & 1 & 1 & 0 & 0 \\
\hline Murgese & 2 & 2 & 0 & 0 \\
\hline Trotter & 1 & 1 & 0 & 0 \\
\hline All $^{\mathrm{b}}$ & 1035 & 1027 & 8 & 0 \\
\hline \multicolumn{5}{|l|}{ Roan horses } \\
\hline Noriker & 51 & 0 & 36 & 15 \\
\hline Quarter Horse & 7 & 0 & 7 & 0 \\
\hline $\begin{array}{l}\text { Slovenian draught } \\
\text { horse }\end{array}$ & 3 & 0 & 3 & 0 \\
\hline Murgese & 2 & 0 & 2 & 0 \\
\hline Belgian draught horse & 1 & 0 & 0 & 1 \\
\hline Shetland Pony & 3 & 3 & 0 & 0 \\
\hline Trakehner & 1 & 1 & 0 & 0 \\
\hline German Sport horse & 3 & 3 & 0 & 0 \\
\hline All $^{\mathrm{b}}$ & 71 & 7 & 48 & 16 \\
\hline
\end{tabular}

${ }^{a}$ for the 379 gray Lipizzan horses the underlying coat color was not known, but roan color is known to segregate in a specific mare family.

b Fisher's exact test for genotype association (A/A and G/-) with roan/non roan coat color for the entire sample revealed a $P$-value $P<.001$. further explore the genome region around the associated top-SNP AX-103594067 and to better understand the underlying genetic background of roan coat color in horses.

\section{Material and Methods}

\subsection{Genome-wide SNP (Single Nucleotide Polymorphism) Data and Genome-wide Association Analysis}

From previous studies [30-33] 670k SNP data for a total of 1012 horses was available, including the following breeds: 140 Noriker, 36 Akhal Teke, 33 Shagya Arabian, 80 Franches Montagnes, 23 Bosnian Mountain Horse, 28 Posavina, 20 Gidran, 389 Lipizzan, two Quarter horses, two Shetland Ponies, three Slovenian draught horses, and 256 Exmoor Ponies (Table 1).

The GWAS was performed, including 40 Noriker horses using a case-control design (case-group: 14 blue roan Noriker horses, control-group: 26 black Noriker horses) and associations were corrected for multiple testing using the Fisher's exact test. SNP extraction and GWAS were performed using the software package PLINK v.1.7 [34]. Quality control (QC) and SNP filtering were applied on the Noriker data set using a minor allelic frequency (MAF) threshold of $<0.01$. After QC, a total of genome-wide 464,880 SNPs were included in the GWAS.

For the verification of genotype and haplotype distribution of roan/non-roan horses of the entire multibreed data set, we applied Fisher's exact test. Statistical analyses and graphical representations were performed using the R-platform (www.r-project.com).

\subsection{Genotyping}

For further verification of our top SNP (AX-103594067) and further putative variants, we genotyped 97 horses (roan/non-roan), including the following breeds: Noriker (26/38), Quarter horse (7/ 5), Appaloosa (0/2), Murgese (2/2), Belgian draught horse (1/0), Slovenian draught horse (3/0), Shetland Pony (3/2), Trakehner (1/ 0 ), Trotter $(0 / 1)$, Warmblood (3/1) (Table 1$)$. In addition, we genotyped 11 archived roan Noriker horses only for the top SNP (AX- 


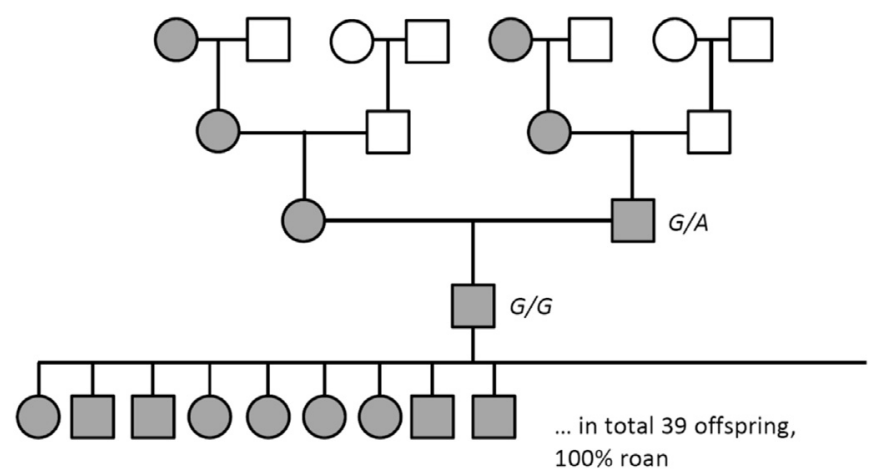

Fig. 2. Pedigree information of the roan stallion NO180 given as an example for the segregation of roan coat color in Noriker horses. Stallions are illustrated by squares, mares by circles; roan phenotype is represented by gray color, non-roan phenotype by white color. On the bottom NO180, homozygous G/G at the top SNP AX-103594067 (ECA3:g.79,543,439A > G), and his 100\% roan offspring, including 39 foals are shown.

103594067). Genomic DNA was isolated from hair roots using nexttecTM Tissue \& Cells Kit, following the manufacturer's protocol. For genotyping, competitive allele-specific PCR SNP genotyping assays (KASP) were used. LGC KASP assays were designed to genotype five variants (Table 3 ) using the LGC service (http://www. lgcgroup.com). KASP screening was performed as described by the supplier on a CFX96 Touch Real-Time PCR Detection System.

\subsection{Pedigree- and ROH Analysis}

The genotype plausibility (checking sire and dam coat color, offspring ratios) of 51 roan Noriker horses were examined, including the pedigree information of 55.567 horses from the Noriker studbook [35]. Furthermore, we performed a ROH analysis for eight roan Noriker horses homozygous $G$ for the top-SNP AX103594067 with an overlapping window approach as implemented in PLINK v1.7 [34] based on the following settings: minimum SNP density of ROH segments was set to one SNP per $50 \mathrm{~kb}$ with a maximum gap length of $50 \mathrm{~kb}$; final segments were called runs of homozygosity $(\mathrm{ROH})$ if the minimum length of the homozygous segment was greater than $125 \mathrm{~kb}$ and comprised more than 20 homozygous SNPs; one heterozygote and one missing genotype were permitted within each segment.

The whole-genome sequence of one blue roan (black base color) Noriker stallion (NO180), verified as homozygous for the roan factor [28], was available from [29]. The variant callings from NO180 (published in [29]) in the ROH region of homozygous Noriker horses, spanning the KIT gene (ECA3:79,472,667-79,694,802), were comparatively analyzed with the sequences published for 87 horses from different breeds [29] (4 Akhal-Teke, 4 American Paint Horse, 1 American Standardbred, 2 Arabian, 1 Polish Warmblood, 3 German Warmblood, 29 Franches-Montagnes, 4 Haflinger, 2 Hannoveraner, 8 Holsteiner, 2 German Riding Pony, 1 Morgan Horse, 4 Icelandic, 1 Dutch Warmblood, 3 Oldenburger, 3 Quarter Horse, 4 Swiss Warmblood, 3 Shetland Pony, 1 Thoroughbred, 3 Trakehner, 2
UK Warmblood, 2 Welsh Pony). For the majority of these horses (84), information on coat color phenotypes was provided for the present study (Suppl. 1). Among the 84 horses with color phenotypes and whole-genome information [29], three Quarter horses were roan. However, although the roan coat color is known in a variety of horse breeds, the overall incidence of roan horses in the sample set of the 88 horses with whole-genome information [29] remained low. Accordingly, we filtered the variant calls published in [29] for positions on ECA3:79,472,667-79,694,802 that are homozygous in NO180 and called at maximum in five additional horses.

Finally, a comparison analysis between the variants identified by Marklund et al. [25] in the Belgian draught horse and the variants inferred in this study was conducted.

\section{Results}

The GWAS in 40 Noriker horses revealed eight SNPs on ECA3 that were significantly associated with roan coat color. These variants were located in the KIT genic region (Fig. 1). The top-SNP (AX103594067, ECA3:g.79,543,439A > G,) was either heterozygous or homozygous for the alternate allele in 64 roan horses (51 Noriker, three Slovenian draught horses, seven Quarter horses, two Murgese horses, and one Belgian draught horse), whereas all non-roan horses were homozygous for the wildtype-allele $(A / A)$ (Table 2). One-third of the roan Noriker horses $(\mathrm{n}=15)$ and one Belgian draught horse were homozygous for the roan associated $G$ allele (Table 2). The $G$ allele was not present in three roan Shetland Ponies, one roan Trakehner, and three roan German Sport horses. In Table 2, the genotype distribution for the top-SNP AX-103594067 of 1036 non-roan horses and 71 roan horses is illustrated. Among 379 gray Lipizzan horses, eight heterozygous $A / G$ carriers could be detected (Table 2).

Pedigree analyses of roan Noriker horses were in concordance with the genotyping results and supported a homozygous state and the dominant mode of inheritance. Eight of the investigated roan Noriker horses with homozygous state $G / G$ of the top SNP AX103594067 had 72 documented offspring, whereas 70 horses were roan, one colt was leopard-spotted, and one foal was tobiano. In Fig. 2 the pedigree information of the sequenced Noriker stallion (NO180) is presented. Based on 670K SNP chip data from eight roan Noriker horses homozygous $G$ for the top-SNP AX-103594067, we identified a $222 \mathrm{~kb}$ homozygous region from ECA3:79,472.667-79,694.802 containing the entire KIT gene. The comparative sequence analysis of the region ECA3:79,472,667-79,694,802 in 88 horses [29], resulted in a total of 1552 variants. Assuming that the roan factor should be present in a homozygous state in animal NO180, 314 variants remained, from which 88 variants were private for this animal. Applying a filter that allows five animals to share these variants, 115 candidate variants were retained. Finally, we selected two regions (A and B) harboring structural variants as putative candidate loci for roan coat color. In the $3^{\prime}$-flanking region of KIT (region A), three deletions were identified and in intron 20 of the KIT gene (Region B), a 3 bp

Table 3

Location, reference allele (REF) and alternate allele (ALT) for the three deletions found in region A (A1, A2, A3), the top-SNP AX-103594067 from the GWAS (SNV) and the insertion in region $\mathrm{B}$ (B1) associated with roan coat color.

\begin{tabular}{lll}
\hline Variant & Position on EquCab3 & REF \\
\hline A1 & ECA3:79,531,997_79,532,011 & TTCCATGATTAATTA \\
A2 & ECA3:79,533,217_79,533,224 & CTCGTCTT \\
A3 & ECA3:79,533,282_79,533,285 & TTCT \\
SNV & ECA3:79,543,439 & A \\
B1 & ECA3:79,588.127-29 & ACA \\
\hline
\end{tabular}


Table 4

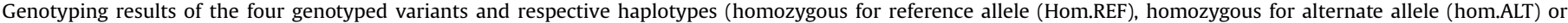
heterozygous (Het.), roan horses without the roan haplotype, are marked with*.

\begin{tabular}{|c|c|c|c|c|c|c|}
\hline Non-roan horses & $\mathrm{n}$ & Haplotype & A2 (3:79533214) & A3 (3:79533281) & SNP (3:79543439) & B1 (3:79588127-29) \\
\hline Noriker & 38 & $00-0-0 / 00-0-0$ & Hom.REF & Hom.REF & Hom.REF & Hom.REF \\
\hline Quarter Horse & 5 & $00-0-0 / 00-0-0$ & Hom.REF & Hom.REF & Hom.REF & Hom.REF \\
\hline Appaloosa & 2 & $00-0-0 / 00-0-0$ & Hom.REF & Hom.REF & Hom.REF & Hom.REF \\
\hline Murgese & 2 & $00-0-0 / 00-0-0$ & Hom.REF & Hom.REF & Hom.REF & Hom.REF \\
\hline Trotter & 1 & $00-0-0 / 00-0-0$ & Hom.REF & Hom.REF & Hom.REF & Hom.REF \\
\hline German Sport horse & 1 & $00-0-0 / 00-0-0$ & Hom.REF & Hom.REF & Hom.REF & Hom.REF \\
\hline Shetland Pony & 2 & $00-0-0 / 00-0-0$ & Hom.REF & Hom.REF & Hom.REF & Hom.REF \\
\hline All $^{\mathrm{a}}$ & 51 & & & & & \\
\hline \multicolumn{7}{|l|}{ Roan horses } \\
\hline Noriker & 18 & $11-1-1 / 00-0-0$ & Het. & Het. & Het. & Het. \\
\hline Noriker & 8 & $11-1-1 / 11-1-1$ & Hom.ALT & Hom.ALT & Hom.ALT & Hom.ALT \\
\hline Quarter Horse & 7 & $11-11 / 00-0-0$ & Het. & Het. & Het. & Het. \\
\hline Slov.Coldblood & 3 & $11-1-1 / 00-0-0$ & Het. & Het. & Het. & Het. \\
\hline Belgian Draught & 1 & $11-1-1 / 11-1-1$ & Hom.ALT & Hom.ALT & Hom.ALT & Hom.ALT \\
\hline Murgese & 2 & $11-1-1 / 00-0-0$ & Het. & Het. & Het. & Het. \\
\hline Shetland Pony* & 3 & $00-0-0 / 00-0-0$ & Hom.REF & Hom.REF & Hom.REF & Hom.REF \\
\hline Trakehner* & 1 & $00-0-0 / 00-0-0$ & Hom.REF & Hom.REF & Hom.REF & Hom.REF \\
\hline German Sport horse* & 3 & $00-0-0 / 00-0-0$ & Hom.REF & Hom.REF & Hom.REF & Hom.REF \\
\hline All $^{\mathrm{a}}$ & 46 & & & & & \\
\hline
\end{tabular}

${ }^{a}$ Fisher's exact test for haplotype association (Hom.REF and Hom.ALT/Het.) with roan/non-roan coat color for the entire sample revealed a $P$-value $P<.001$.

deletion combined with 17 bp insertion was detected (Table 3). All five variants were homozygous for the alternate allele (ALT) in the Noriker stallion N0180. LGC KASP assays were designed for the genotyping of the associated top SNP AX-103594067 from the $670 \mathrm{~K}$ SNP Chip, the three deletions located downstream of the KIT gene (A1-A3) and the $3 \mathrm{bp}$ deletion combined with $17 \mathrm{bp}$ insertion in intron 20 of KIT (B1). The genotyping results revealed that the deletion A1 was not roan specific, and was, therefore, excluded from further analyses.

The remaining two deletions ( $\mathrm{A} 2$ and $\mathrm{A} 3$ ) and the 3 bp deletion combined with $17 \mathrm{bp}$ insertion (B1) were solely detected in roan horses for the breeds Noriker, Quarter Horse, Murgese, Slovenian and Belgian draught horse. These three loci were in complete LD with the top SNP AX-103594067 at ECA3g:79,543,439A > G and the resulting roan-associated haplotype was assigned 11-1-1 (variants phased, $\mathrm{REF}=0, \mathrm{ALT}=1$ ) (Table 4., Fig. 3). This roan haplotype was not present in three roan German Sport Horses and one roan Trakehner and three roan Shetland Ponies. All these animals exhibited the same haplotype (00-0-0) as non-roan horses.

The comparison of the identified variants with the regions associated with roan coat color by Marklund et al. [25] showed a close proximity, especially for the SNP AX-103594067 (Table 5), and two roan associated sites of Marklund et al. [25] (ECA3:79,545,912G $>$ A in site SSCP, ECA3:79,540,501G $>$ A in site Taql) were confirmed in the homozygous stallion NO 180 (Table 5).

\section{Discussion}

For a long time, the homozygous state of a dominant roan coat color allele was supposed to be lethal in utero according to
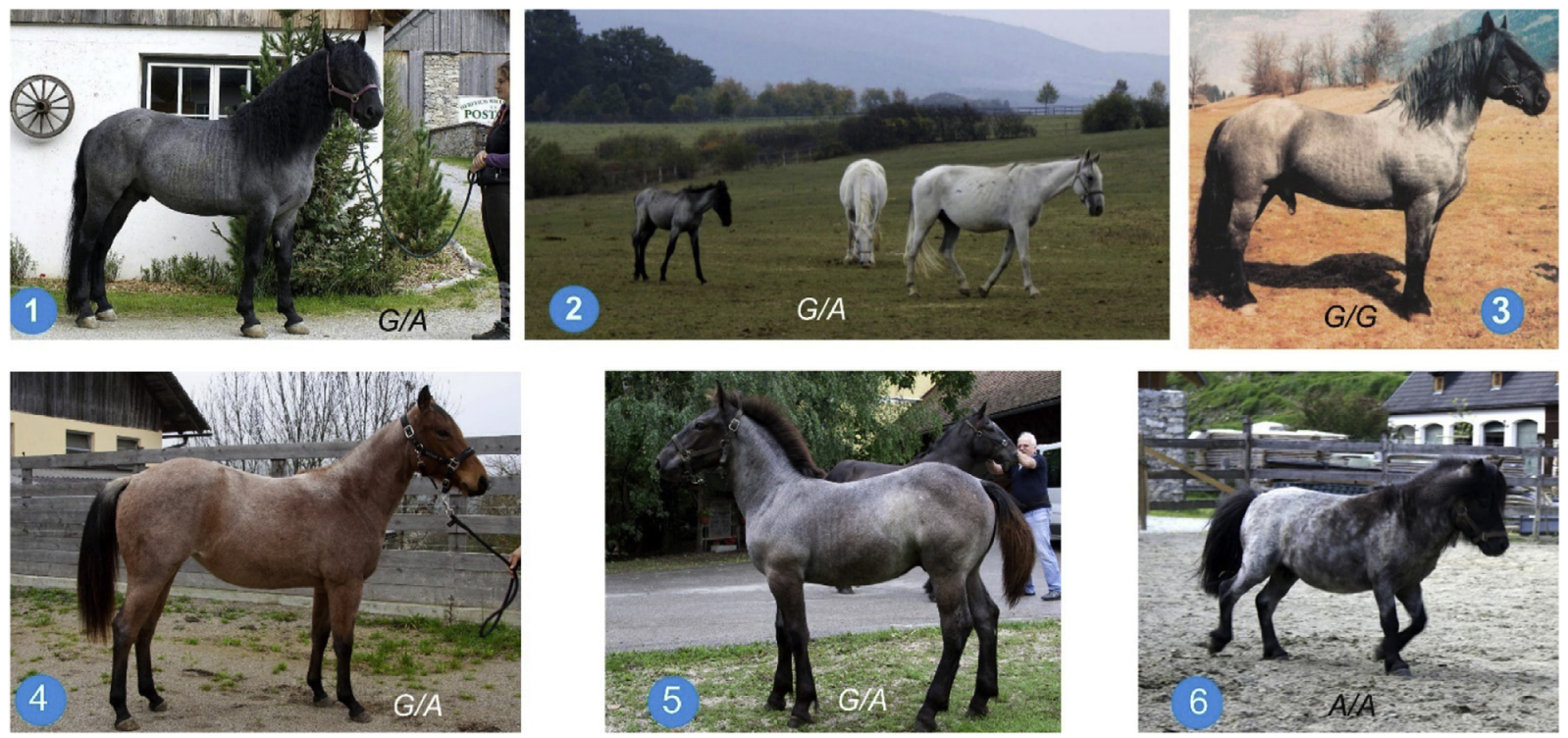

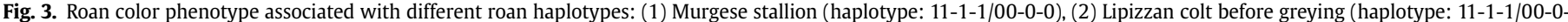

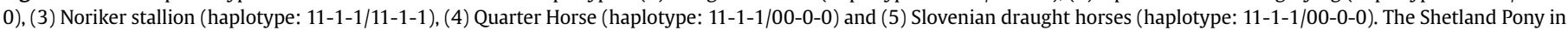
(6) is not carrying the reported roan haplotype (haplotype: 00-0-0/00-0-0) (images by Grilz-Seger, Mesaric, archive Druml). 
Table 5

Distance between the top SNP AX-103594067 and the sites associated with roan coat color by Marklund et al. (1999).

\begin{tabular}{|c|c|c|c|c|c|c|}
\hline ID & Study & position & Distance to top-SNP & N0180 & REF & ALT \\
\hline Cfol & Marklund et al. (1999) & ECA3:79,538,738 & $4701 \mathrm{bp}$ & Hom.REF & $\mathrm{C}$ & $\mathrm{T}$ \\
\hline TaqI & Marklund et al. (1999)/this study & ECA3:79,540,501 & 2938 bp & Hom.ALT & G & A \\
\hline SNV & this study & ECA3:79,543,439 & & Hom.ALT & A & G \\
\hline SSCP & Marklund et al. (1999)/this study & ECA3:79,545,912 & 2473 bp & Hom.ALT & G & A \\
\hline
\end{tabular}

offspring ratios [25,26]. Sponenberg and Bellone [27] proposed the existence of living homozygous $\mathrm{Rn} / \mathrm{Rn}$ roan horses, which was confirmed in our study.

Marklund et al. (1999) [25] reported an incomplete association between roan phenotype and genotype information in 33 roan and 92 nonroan horses, mapped to the KIT gene. With the investigation of additional breeds (Welsh, Shetland, and Gotland Pony), the level of association declined, which led the authors to assume genetic heterogeneity. Our study recapitulates these findings as the genetic association for roan coat color was not complete. However, we found a complete association between a roan haplotype in Noriker and further draught horses (Belgian and Slovenian draught horse), as well as Murgese, and seven Quarter horses of our dataset. The identified roan haplotype was not present in three roan Shetland Ponies, three German Warmblood horses, and one Trakehner. The three roan Quarter horses published in [29] did also not exhibit the roan haplotype. Our four sampled roan German Sport horses and Trakehner horses all descended from the same stallion and might carry a very rare roan allele. The existence of breed-specific segregation of coat color alleles is well known for Sabino (SB1) and chestnut $(M C 1 R)$ [11,36]. The SB1 allele associated with the Sabino phenotype was firstly detected in the Tennessee Walking horse [11], and it was further documented in numerous breeds, including American Miniature, Paint Horse, Azteca, Missouri Foxtrotter, Shetland Pony, and Spanish Mustang. Brooks et al. [11] further demonstrated that within breeds with the classical Sabino phenotype like Shire Horse or Clydesdale, the SB1 allele did not segregate, a result that was also confirmed by Reissmann et al. [37]. Further allelic heterogeneity at the KIT locus was reported for Dominant White, where several breeds or even family-specific mutations are responsible for depigmented phenotypes in horses [38].

The breed-specific segregation of roan associated alleles may be explained by the population history of the breeds. Roan coat color represented a major breeding objective in Old-Italian and OldSpanish horse populations before 1800 [39,40]. The breeds Lipizzan, Murgese, Noriker, Slovenian draught horse (mainly derived from Noriker horses), Belgian draught horse, and Quarter Horse, are directly connected to this baroque gene pool or founder populations are proven by either pedigree or historical records.

For the draught horse breeds in this sample, a direct connection to the baroque gene pool can be found in imperial stud farms established in original breeding areas of respective breeds: for example, in the clerical stud farm Rif near Salzburg, which interacted with local breeding (horse in Noriker-like type), roan horses were already recorded in the year 1652 [41]. A similar gene-flow between a baroque gene pool and local working horse populations of later on Belgian draught horse type like horses and introgression of roan can be assumed from the imperial stud farm Alost, founded by the Austrian empire in Belgium in 1770 [42].

In our sample, Shetland Ponies and breeds derived from English Thoroughbred were characterized by the absence of the roan associated $G$-allele and haplotype, and thus, the roan phenotype in these breeds may be traced back to another founder population. Introgression of single dominant inherited traits was mainly conducted using single breeding animals, especially stallions. Y- chromosomal studies [43] revealed that Northern European Pony breeds and the Thoroughbred cluster show distinct population history and genetic distances to the core clusters, which mainly evolved from a unique group, including the descendant breeds from a prior baroque gene pool.

\section{Conclusion}

Our results suggest the SNP AX-103594067 (ECA3g:79,543,439A $>G$ ) in the KIT gene as a genetic marker for roan coat color in Noriker horses and as a putative marker in draught horse breeds, Lipizzans and Murgese. Our data supports the previously postulated allelic heterogeneity in roan horses, as the marker was not identified in roan Shetland ponies and roan Thoroughbred-related breeds. To validate the marker and the associated roan haplotype in other breeds than Noriker, we suggest further investigation within a bigger panel comprising additional multibreed samples.

\section{Acknowledgments}

We want to thank the Austrian, Slovenian horse breeding associations and Viktoria Remer for supporting data collection, Annik Gmel for DNA extraction. The Exmoor Pony Society in the UK is thanked for the sampling of horses.

Funding: This work was financially supported by the Austrian Research Promotion Agency (FFG), Contract number 843464; the Federal Ministry for Sustainability and Tourism (BMNT), Contract number 101332, and Slovenian Research Agency program P4-0053 to M. Cotman. Data collection and genotyping of the Exmoor Pony received funding from the European Union's Seventh Framework Program managed by REA-Research Executive Agency; http://ec. europa.eu/research/rea (FP7/2007-2013) under grant agreement no. 606142 and The Exmoor Pony Society in the UK, and grant 31003A_172964 of the Swiss National Science Foundation.

\section{Supplementary data}

Supplementary data to this article can be found online at https://doi.org/10.1016/j.jevs.2020.102950.

\section{References}

[1] Marklund L, Moller MJ, Sandberg K, Andersson L. A missense mutation in the gene for melanocyte-stimulating hormone receptor (MC1R) is associated with the chestnut coat color in horses. Mamm Genome 1996;7:895-9.

[2] Rieder S, Taourit S, Mariat D, Langlois B, Guerin G. Mutation in the agouti (ASIP), the extension (MC1R), and the brown (TYRP1) loci and their association to coat color phenotypes in horses (Equus caballus). Mamm Genome 2001;12:450-5.

[3] Mariat D, Taourit S, Guérin G. A mutation in the MATP gene causes the cream coat color in the horse. Genet Sel Evol 2003;35:119-33.

[4] Imsland F, McGowan K, Rubin C], Henegar C, Sundström E, et al. Regulatory mutations in TBX3 disrupt asymmetric hair pigmentation that underlies Dun camouflage color in horses. Nat Genet 2016;48:152-8.

[5] Cook D, Brooks S, Bellone R, Bailey E. Missense mutation in exon 2 of SLC36A1 responsible for champagne dilution in horses. PLoS Genet 2008;4:e1000195.

[6] Brunberg E, Anderson L, Cothran G, et al. A missense mutation in PMEL17 is associated with the Silver coat color in the horse. BMC Genet 2006;7:46. 
[7] Pielberg RG, Golovko A, Sundström E, Curik I, Lennartsson J. A cis-acting regulatory mutation causes premature hair graying and susceptibility to melanoma in the horse. Nat Genet 2008;40:1004-9.

[8] Bellone R, Holl H, Setulari V, et al. Evidence for a retroviral insertion in TRPM1 as the cause of congenital stationary night blindness and leopard complex spotting in the horse. PLoS One 2013;8:e78280.

[9] Holl HM, Brooks SA, Archer S, Brown K, Malvick J, Penedo MC, Bellone RR. Variant in the RFWD3 gene associated with PATN1, a modifier of leopard complex spotting. Anim Genet 2016;47:91-101.

[10] Yang GC, Croaker D, Zhang A, Manglick P, Cartmill T, Cass D. A dinucleotide mutation in the endothelian-B receptor gene is associated with letal white foal syndrome (LWFS) - a horse variant of Hirschprung-disease (HSCR). Hum Mol Genet 1989;7:1047-52.

[11] Brooks S, Bailey E. Exon skipping in the KIT gene causes a Sabino spotting pattern in Horses. Mamm Genome 2005;16:893-902.

[12] Brooks S, LearT, Adelson L, Bailey E. A chromsome inversion near the KIT gene an the Tobiano spotting pattern in horses. Cytogenet Genome Res 2007;119:225-30.

[13] Haase B, Brooks SA, Schlumbaum A, Azor PJ, Bailey E, Alaeddine F, Mevissen M, Burger D, Poncet PA, Rieder S, Leeb T. Allelic heterogeneity at the equine KIT locus in dominant white (W) horses. PLoS Genet 2007;3:e195.

[14] Haase B, Brooks SA, Tozaki T, Burger D, Poncet PA, Rieder S, Hasegawa T, Penedo C, Leeb T. Seven novel KIT mutations in horses with white coat color phenotypes. Anim Genet 2009;40:623-9.

[15] Holl H, Brooks S, Bailey E. De novo mutation of KIT discovered as a result of a non-hereditary white coat color pattern. Anim Genet 2010;41(Suppl 2):196-8.

[16] Haase B, Rieder S, Tozaki T, Hasegawa T, Penedo MC, Jude R, Leeb T. Five nove KIT mutations in horses with white coat color phenotypes. Anim Genet 2011;42:337-9.

[17] Hauswirth R, Jude R, Haase B, Bellone RR, Archer S, Holl H, Brooks SA, Tozaki T, Penedo MC, Rieder S, Leeb T. Novel variants in the KIT and PAX3 genes in horses with white-spotted coat color phenotypes. Anim Genet 2013;44: 763-5.

[18] Haase B, Jagannathan V, Rieder S, Leeb T. A novel KIT variant in an Icelandic horse with white-spotted coat color. Anim Genet 2015;46:466.

[19] Holl HM, Brooks SA, Carpenter ML, Bustamante CD, Lafayette C. A novel splice mutation within equine KIT and the W15 allele in the homozygous state lead to all white coat color phenotypes. Anim Genet 2017;48:497-8.

[20] Dürig N, Jude R, Holl H, Brooks SA, Lafayette C, Jagannathan V, Leeb T. Whole genome sequencing reveals a novel deletion variant in the KIT gene in horses with white spotted coat color phenotypes. Anim Genet 2017;48:483-5.

[21] Capomaccio S, Milanesi M, Nocelli C, Giontella A, Verini-Supplizi A, Branca M, Silvestrelli M, Cappelli K. Splicing site disruption in the KIT gene as strong candidate for white dominant phenotype in an Italian Trotter. Anim Genet 2017;48:727-8.

[22] Hoban R, Castle K, Hamilton N, Haase B. Novel KIT variants for dominant white in the Australian horse population. Anim Genet 2018;49:99-100.

[23] Hug P, Jude R, Henkel J, Jagannathan V, Leeb T. A novel KIT deletion variant in a German Riding Pony with white-spotting coat color phenotype. Anim Genet 2019;50:761-3.

[24] Hauswirth R, Haase B, Blatter M, Brooks SA, Burger D, Drögemüller C, et al. Mutations in MITF and PAX3 cause "splashed white" and other white spotting phenotypes in horses. PLoS Genet 2012;8:e1002653.
[25] Marklund S, Moller M, Sandberg K, Andersson L. Close association between sequence polymorphism in the KIT gene and the roan coat color in horses. Mamm Genome 1999;10:283-8.

[26] Hintz HF, Van Vleck LD. Lethal dominant roan in horses. J Hered 1979;70: 145-6.

[27] Sponenberg DP, Bellone R. Equine color genetics. 4th ed. Ames: WileyBlackwell; 2017.

[28] Grilz-Seger G, Neuditschko M, Wallner B, Horna M, Brem G, Druml T. Association of roan coat color with KIT in Noriker draught horses. Prag: Poster, Animal Science Days; 2019.

[29] Jagannathan V, Gerber V, Rieder S, Tetens J, et al. Comprehensive characterization of horse genome variation by whole-genome sequencing of 88 horses. Anim Genet 2018:50:74-7.

[30] Grilz-Seger G, Druml T, Neuditschko M, Mesarič M, Cotman M, Brem G. Analysis of ROH patterns in the Noriker horse breed reveal signatures of selection for coat color and body size. under review. Anim Genet 2019;50: 334-46.

[31] Grilz-Seger G, Druml T, Neuditschko M, Dobretsberger M, Horna M, Brem G. High-resolution population structure and runs of homozygosity reveal the genetic architecture of complex traits in the Lipizzan horse. BMC Genomics 2019;20:174.

[32] Grilz-Seger G, Neuditschko M, Ricard A, Velie BD, Lindgren G, et al. Genomewide homozygosity patterns and evidence for selection in a set of European and near Eastern horse breeds. Genes (Basel) 2019;10:491.

[33] Gmel A, Druml T, Niederhäusern R, Leeb T, Neuditschko M. Genome-wide association studies based on equine joint angle measurements reveal new QTL affecting the conformation of horses. Genes (Basel) 2019;10:370.

[34] Purcell S, Neale B, Todd-Brown K, Thomas L, Ferreira MA, Bender D, Maller J, Sklar P, de Bakker PI, Daly MJ, et al. PLINK: a tool set for whole genome association and population-based linkage analyses. Am J Hum Genet 2007;81: $559-75$.

[35] ARGE Noriker. PDV Database export. Stadl-Paura, Austria: Arbeitsgemeinschaft (ARGE) Noriker; 2019.

[36] Wagner HJ, Reissmann M. New polymorphism detected in the horse MC1R gene. Anim Genet 2000;31:289-90.

[37] Reissmann M, Musa L, Zkizadech S, Ludwig A. Distribution of coat-colorassociated alleles in the domestic horse population and Przewalski's horse. J Appl Genet 2016;57:519-25.

[38] Haase B, Brooks SA, Schlumbaum A, Azor PJ, Bailey E, Alaeddine F, Mevissen M, Burger D, Poncet PA, Rieder S, Leeb T. Allelic heterogeneity at the equine KIT locus in dominant white (W) horses. PLoS Genet 2007;3:e195.

[39] Buonavolontà G, Silvestrelli M, editors. Il murgese. Italy: Equestri, Milano; 1986.

[40] Grilz-Seger G, Druml T. Lipizzaner hengststämme. Graz, Austria: Vehling Verlag; 2011.

[41] Grilz-Seger G, Druml T. Das Noriker Pferd. Band II. Graz, Austria: Vehling Verlag; 2012.

[42] De Theulegoet H. Monographie des Belgischen Lastpferdes. Germany: Hannover; 1912.

[43] Wallner B, Palmieri N, Vogl C, Rigler D, Bozlak E, Druml T, Jagannathan V, et al. $Y$ chromosome uncovers the recent oriental origin of modern stallions. Curr Biol 2017;27:2029-2035.e5. 